\title{
Autonomy of Ethics
}

Frank Jackson

\section{Introduction}

One question is how things are. Another question is how they ought to be, including what ought to be done. But the two questions are intimately connected. My judgment that I ought to support Oxfam is based on what I believe Oxfam would do with a donation. Your belief that you ought to vote for a certain candidate is based on what you believe the candidate would do if elected. The autonomy of ethics is a thesis about the nature of the passage from how things are to how things ought to be, including especially what ought to be done. As traditionally conceived since Hume (A Treatise of Human Nature [1740], Bk. III, Pt. 1, \$1; see HUME, DAVID), the thesis is that we cannot deduce how things ought to be or what ought to be done from how things are, or as it is often put, we cannot deduce, in the sense of a priori infer, an "ought" from an "is."

The thought behind the thesis, the surely plausible thought even for those who in the end reject it, is that the step from what is to what ought to be done, is always a step in a substantive sense (see IS-OUGHT GAP). Knowing the facts is one thing; coming to a judgment about what ought to be done given the facts is another. This means that knowing the facts, no matter how comprehensive, always leaves open, in some significant sense, the question of what ought to be done (Moore 1903: \$13; Hare 1961: 29; see MOORE, G. E.; HARE, R. M.).

Despite the simplicity with which our thesis can be posed and the case for it sketched, there are a number of questions concerning how, precisely, we should understand it. We will look at some issues of interpretation before reviewing some of the arguments for and against the autonomy of ethics.

\section{Issues of Interpretation}

Consider the following inference

$X$ is morally wrong

Therefore, $X$ ought not to be done.

This is an inference from an "is" to an "ought," and one that is plausibly a priori valid. Isn't it part of the meaning of "morally wrong" that any action that is morally wrong ought not to be done? It might seem that we can reject the autonomy of ethics without further ado. 
This would be too quick. The autonomy of ethics needs to be understood against a background which divides expressions into two classes: the moral and the nonmoral or the normative and the descriptive, or the ethical and the factual, or .... Terminology varies. We will talk in terms of the moral versus the nonmoral (but it should be noted that many of the issues that come up in discussions of the autonomy of ethics also come up when discussing normativity in general; see NORMATIVITY). In terms of the distinction between moral and nonmoral language, the autonomy of ethics claims that no inference from premises framed in purely nonmoral terms to a conclusion framed in moral terms is valid. The inference above fails to be a counterexample to the thesis so understood because its premise includes moral terms, in particular the word "wrong."

But what precisely is the distinction between moral and nonmoral expressions? The response just given to a putative counterexample presupposes that "wrong" is a moral expression, and one might think of the moral terms as made up of, say, "right," "wrong," "good," "bad," and "ought," and their synonyms. But now consider the inference

$X$ is a case of murder

Therefore, $X$ is wrong.

This inference is plausibly a priori valid. Isn't it part of the meaning of "murder" that any act that counts as murder is wrong? This is why an intentional killing that is a case of justified self-defense is not a case of murder.

A defender of autonomy might respond by adding "murder" to their list of moral expressions. This would mean that the inference immediately above would not be a case of deducing a moral conclusion from a nonmoral premise. But now they have trouble with

$X$ is not a killing

Therefore, $X$ is not a case of murder.

If "murder" is a moral expression, it is hard to see why this inference would not count as the deduction of a moral conclusion (albeit one with a negative cast) from a nonmoral premise.

Where does this leave the autonomy of ethics? One response is to insist that expressions like "murder" can be thought of as conjunctions of the properly moral and the nonmoral or descriptive. Roughly, the idea is that a murder is an intentional killing that is wrong. A distinction is drawn between thin moral expressions like "right," "wrong," and "ought," and thick ones like "murder" and "courageous." The thin ones are the properly moral expressions and the claim is that the thick expressions can be analyzed into a thin part and a nonmoral part along the lines we illustrated for "murder." The defender of the autonomy of ethics then argues that their thesis should be framed in terms of thin or purely moral expressions and nonmoral ones. The thesis is, that is to say, that no inference from a premise or premises framed in nonmoral terms - that is, in terms that are neither thin nor thick moral terms - to a conclusion framed in purely moral or thin terms is a priori valid. 
Moreover, even if one rejects the program of reducing the thick to the thin plus the nonmoral as misguided (for discussion, see FACT-VALUE DISTINCTION; THICK AND THIN CONCEPTS), the thesis that no inference from a premise or premises framed in nonmoral terms to a conclusion framed in thin moral terms is a priori valid is one well worth discussing. It wouldn't perhaps be, strictly speaking, an autonomy of ethics thesis; it would be an autonomy of a fragment of ethics thesis. But no great matter.

However, even with this restriction in place, there is still interpretative trouble for defenders of autonomy. Consider (the example that follows is modified from Prior 1960; for more detailed discussion and additional references see Jackson 1974; it should be noted that Prior thought he was making a major objection to the autonomy of ethics, not merely raising a problem of interpretation)

Tea drinking is common

Therefore, tea drinking is common or abortion is wrong

This inference is a priori valid and goes from a purely nonmoral premise to a moral conclusion framed using (thin) moral terms.

The defender of autonomy might understandably reply that the conclusion isn't really a moral one. It is a disjunction which has one nonmoral disjunct and one moral disjunct. But consider the following inference:

Everyone drinks water

Therefore, there is no person who ought to be punished or there is at least one drinker of water who ought to be punished

This inference is a priori valid and both disjuncts are framed using moral terms.

All the same, a natural reaction to this example (and the previous one if it comes to that) is that it is a "trick" example of no relevance to real-life debates in ethics. The defender of the autonomy of ethics might well insist that the essential insight behind the doctrine is correct. However, there are a priori valid inferences not unlike those we have been discussing that figure in "real-life" reflections on important moral questions.

Suppose Jane has serious reservations about abortion but nevertheless agrees to pay for a close friend's abortion. For her the a priori valid inference

I have paid for an abortion

Therefore, if anyone who has paid for an abortion has done something morally wrong, I have done something morally wrong

corresponds to a line of reasoning that worries her a great deal.

There is, therefore, an important question about how, precisely, to state the autonomy of ethics. Despite this, it is fair to say that the inferences we have been discussing lately do not permit the drawing of substantive moral conclusions using noncontroversially a priori valid inferences from the nonmoral to the moral. One way to bring this out is to note that 
I have paid for an abortion

Therefore, if anyone who has paid for an abortion has done something morally right, I have done something morally right

is just as a priori valid as the inference we discussed immediately above. The same point applies to the tea-drinking inference discussed earlier. The inference

Tea drinking is common

Therefore, tea drinking is common or abortion is right

which is the earlier inference with "wrong" replaced by "right," is just as a priori valid as the earlier version.

We should, therefore, think of the autonomy of ethics as insisting that you cannot obtain a categorical moral conclusion (see CATEGORICAL IMPERATIVE) a priori from purely nonmoral premises, while granting that a precise specification of what a categorical moral conclusion comes to may be difficult.

We now turn to the substantive issue.

\section{Supervenience and Autonomy}

Under the influence of Blackburn (1971) and ensuing discussions, the current debate over the autonomy of ethics centers on the implications of the supervenience of the moral on the nonmoral.

It is plausible that differences in moral properties imply differences in nonmoral properties. If one action is right and another wrong, they must differ in how much suffering they cause, the way they cause it, the motives with which they are performed, or ..., where the dots are filled with differences we can capture in nonmoral terms: $X$ and $Y$ cannot differ in moral properties alone is the plausible thought. This means that if $X$ and $Y$ are exactly alike nonmorally, they must be exactly alike morally (see UNIVERSALIZABILITY). When two classes of properties are related in such a way that being exactly alike in respect to the first class implies being exactly alike with respect to the second class, properties in the second class are said to supervene on properties in the first class. Thus what we have been lately saying can be put as that moral properties supervene on nonmoral properties (see SUPERVENIENCE, MORAL).

We learn, therefore, from the supervenience of the moral on the nonmoral, that there is $a$ sense in which ethics isn't autonomous. The nonmoral fixes the moral without remainder. The moral cannot be varied independently of the nonmoral. What is more, the argument to this result steers clear of the issues about how, precisely, to divide the moral from the nonmoral that we touched on in our discussion of the distinction between thick and thin moral expressions. Provided, as is plausible, that there is some way of dividing the moral from the nonmoral consistent with the supervenience of the moral on the nonmoral, we have a simple argument to the conclusion that the nonmoral necessitates the moral. 
How can the defender of the autonomy of ethics respond? One way is to argue that this conclusion is consistent with the autonomy of ethics understood as the denial of patterned connections running from the nonmoral to the moral. A second way is to argue that the conclusion that comes from supervenience is consistent with the autonomy of ethics understood as the denial that the nonmoral a priori determines the moral (which is, as we saw, the way autonomy is traditionally understood). A third way is to view the issue through the lens of an expressivist or non-cognitivist construal of ethical discourse (see NON-COGNITIVISM). We will review these responses in turn.

\section{Supervenience and Patterns}

Suppose a computer assigns numbers to objects according to their shape: one number for each distinct shape. The assignment is random as far as the shapes are concerned. This ensures that if $X$ and $Y$ are the same shape, $X$ 's number will be the same as $Y$ 's. Numbers assigned to objects will, accordingly, supervene on their shape. But there won't be a patterned connection running from objects' shapes to the assigned numbers over and above the respecting of supervenience. For example, the fact that two objects have different but very similar shapes will be no reason to expect that they have similar numbers assigned to them.

This example tells us that supervenience is consistent with the lack of patterned connections and opens the possibility of defending autonomy construed as the denial of patterned connections running from the nonmoral to the moral. This is a position suggested by some readings of the doctrine known as particularism (see the introduction and papers in Hooker and Little 2000; see PARTICULARISM).

However, autonomy in this sense is hard to square with a pervasive principle operating in moral debates. The principle is that different moral verdicts on similar cases require justification. Many hold that it is morally permissible to eat cows but not morally permissible to eat humans. The challenge from vegetarians is to justify treating the cases differently. Perhaps we can meet this challenge; perhaps we cannot. Either way, it is hard to believe that the challenge is misconceived. The debate over same-sex marriage provides another example. All parties accept that treating same-sex unions differently from heterosexual unions requires justification. The debate is over the implications of this point of agreement. But the principle that different moral verdicts on similar cases require justification presumes that the passage from the nonmoral to the moral is patterned. Indeed, one way of thinking of moral debate is as a massive "compare and contrast" exercise. We seek to make our moral judgments across the range of cases consistent, where this means playing off intuitive moral judgments about cases against plausible principles connecting the nonmoral to the moral that concern the relevant similarities and differences between cases (see REFLECTIVE EQUILIBRIUM). This would be a nonsense if there were no patterned connections running from the nonmoral and the moral. (For more detail, references, and other problems for denying that there is a patterned connection, see Jackson et al. 2000.) 


\section{Determination without $a$ priori Deducibility}

It is widely accepted that the distribution of water determines, as a matter of necessity, the distribution of $\mathrm{H}_{2} \mathrm{O}$. This is because it is widely accepted that it is necessarily true that water is, or is made up of, $\mathrm{H}_{2} \mathrm{O}$ (Putnam 1975; Kripke 1980). If this is right, we have an example of determination in some strong sense that is not a case of $a$ priori deducibility. One cannot a priori deduce the distribution of $\mathrm{H}_{2} \mathrm{O}$ from that of water, because the identity of water with $\mathrm{H}_{2} \mathrm{O}$, although necessarily true, is a posteriori. It was, and had to be, established by experiment. This suggests that we might reconcile the autonomy of ethics with the supervenience of the moral on the nonmoral by holding that it also is a case of determination without a priori deducibility.

This proposal raises an important issue about moral language. The reason many hold that the distribution of water determines, without a priori necessitating, the distribution of $\mathrm{H}_{2} \mathrm{O}$ is that they accept an appealing account of how names of natural kinds like "water" work. In outline it runs as follows. The term "water" entered the language as a term for a kind that made itself known to us as a widely distributed stuff that is typically potable, odorless and colorless, and liquid at room temperature. The term, however, is a name for the kind, and not a name for any widely distributed stuff that is typically potable, odorless and colorless, and liquid at room temperature. This means the reference of "water" is fixed to the kind and entails that finding the kind in question to be $\mathrm{H}_{2} \mathrm{O}$ is finding that water is necessarily $\mathrm{H}_{2} \mathrm{O}$. For it means that what is discovered, despite being an empirical matter, holds true in every possible world. In the absence of an account like this, we would have no reason to hold that water is necessarily $\mathrm{H}_{2} \mathrm{O}$ and, therefore, no reason to hold that the distribution of water determines or necessitates, without a priori entailing, the distribution of $\mathrm{H}_{2} \mathrm{O}$. An important issue, accordingly, for the proposal that the nonmoral necessitates without a priori determining the moral is whether a broadly similar story can be told for moral terms. Many argue that it can (see Brink 1989 and references therein; see NATURALISM, ETHICAL).

\section{Autonomy and Expressivism}

There is a quite different way of defending the autonomy of ethics against the challenge posed by the supervenience of the moral on the nonmoral, one especially championed by Blackburn $(1971,1985)$. It is to think of moral language as expressing attitudes rather than making claims about how things are. On this view, there are, strictly speaking, no moral properties. The role of sentences of the form " $X$ is good" is to express a special kind of pro-attitude toward $X$ by one who produces the sentence; it does not ascribe the property of being good to $X$. Likewise, " $X$ is bad" expresses a special kind of con-attitude toward $X$.

On this view, the supervenience of the moral on the nonmoral cannot be the thesis that moral properties supervene on nonmoral properties, for the view denies that there are any moral properties to do the supervening. Rather, supervenience morphs into a consistency constraint on attitudes. The constraint is that a necessary condition for an attitude, pro or con, toward $X$ to count as a moral attitude is that the 
attitude in question must also be taken to anything exactly like $X$ in nonmoral properties. However, this is consistent with the attitude taken toward $X$, as such, not being determined by the nonmoral; what is determined is only that the attitude must coincide with that taken toward any nonmoral duplicate of $X$. To that extent, if expressivism is true, supervenience allows the moral to float free of the nonmoral provided it does so in an internally consistent manner. Many expressivists see this as one of the best reasons for being an expressivist.

See also: CATEgORICAL IMPERATIVE; FACT-VALUE DiSTINCTION; HARE, R. M.; HUME, DAVID; IS-OUGHT GAP; MOORE, G. E.; NATURALISM, ETHICAL; NONCOGNITIVISM; NORMATIVITY; PARTICULARISM; REFLECTIVE EQUILIBRIUM; SUPERVENIENCE, MORAL; THICK AND THIN CONCEPTS; UNIVERSALIZABILITY

\section{REFERENCES}

Blackburn, Simon 1971. "Moral Realism," in John Casey (ed.), Morality and Moral Reasoning. London: Methuen, pp. 101-24.

Blackburn, Simon 1985. “Supervenience Revisited," in Ian Hacking (ed.), Exercises in Analysis. Cambridge: Cambridge University Press, pp. 47-68.

Brink, David 1989. Moral Realism and the Foundation of Ethics. Cambridge: Cambridge University Press.

Hare, R. M. 1961. The Language of Morals. Oxford: Clarendon Press.

Hooker, Brad, and Margaret Little (eds.) 2000. Moral Particularism. Oxford: Oxford University Press.

Jackson, Frank 1974. "Defining the Autonomy of Ethics," Philosophical Review, vol. 83, pp. 89-96. Jackson, Frank, Michael Smith, and Philip Pettit 2000. "Ethical Particularism and Patterns," in Brad Hooker and Margaret Little (eds.), Moral Particularism. Oxford: Oxford University Press, pp. 79-99.

Kripke, Saul 1980. Naming and Necessity, 2nd ed. Oxford: Blackwell.

Moore, G. E. 1903. Principia Ethica. Cambridge: Cambridge University Press.

Prior, A. N. 1960. "The Autonomy of Ethics," Australasian Journal of Philosophy, vol. 38, pp. 199-206.

Putnam, Hilary 1975. “The Meaning of 'Meaning," reprinted in Mind, Language and Reality. Cambridge: Cambridge University Press, pp. 215-71.

\section{FURTHER READINGS}

Blackburn, Simon 1998. Ruling Passions. Oxford: Oxford University Press.

Gibbard, Allan 1990. Wise Choices, Apt Feelings. Cambridge, MA: Harvard University Press. Hudson, W. D. (ed.) 1969. The Is/Ought Question. London: Macmillan.

Jackson, Frank 1998. From Metaphysics to Ethics. Oxford: Clarendon Press.

Kurtzman, David R. 1970. “'Is', 'Ought', and the Autonomy of Ethics," Philosophical Review, vol. 79, pp. 493-509.

Pigden, C. R. 1989. "Logic and the Autonomy of Ethics," Australasian Journal of Philosophy, vol. 67, pp. 127-51.

Prior, A. N. 1949. Logic and the Basis of Ethics. Oxford: Oxford University Press. 